\title{
Using Communicative Approach for Language Teaching in Sri Lankan Secondary Schools
}

\author{
Ruwini Prasadini Dharmawardene \\ Faculty of Management Studies and Commerce, \\ University of Sri Jayewardenepura
}

\section{Abstract}

English as a second language curriculum in Sri Lankan public schools aims at enhancing knowledge-building through the use of communicative language teaching (CLT) while assisting both the teachers and the learners to solve problems. In this case study, we investigated the extent of teachers' inclination to use the CLT approach. The study was guided by Socio-Cultural Theory (SCT) and the Experiential Learning Theory (ELT). Five purposively selected participants in a popular secondary school in Colombo District in Sri Lanka responded to semi structured interviews and were observed while they were teaching. The analysis revealed that although teachers understood that knowledge-building can be enhanced by CLT they are less prepared to implement it because they lack the skills and the competencies in doing so. Further, teachers prefer to follow traditional pedagogic practices that do not lead to knowledge-building in learners. We recommend that a number of workshops be offered to in-service teachers who follow the Postgraduate Diploma in Education in Universities and the other Teacher Training Institutes on how to employ CLT activities that enhance knowledge-building in the secondary school students.

Keywords: secondary schools, second language teaching, communicative approach, language activities

\section{Introduction}

After the independence in 1948, the Sri Lankan Education system underwent a number of changes. English was made a compulsory second language to be taught in 
all state schools from grade three onwards through the Education Amendment Act of 1951. This initiative narrowed down the gap between English medium schools and vernacular schools. Realizing the negative sociopolitical consequences that could arise due to the instrumental value attached to colonial English, soon after the vernacular languages were made the official languages, Sinhala/ Tamil was made the medium of instruction in schools as well. With these changes, the status given to English in the national curriculum started to decline (Canagarajah, 2011). This drastic change diminished English medium education, putting a threat to the English private schools, which were subsequently forced to follow the state system. Medium of instruction in these schools was the local language instead of English (Raheem \& Devendra, 2007). Though the medium of instruction at tertiary level was English, the free education policy and the importance attributed to vernacular languages in primary and secondary level had a great impact on the medium of instruction used at Universities.

Scholars like Canagarajah (2011) have supported curriculum change by explaining that it enables teachers and stakeholders in the educational sector to reflect on teaching and learning content and methods and keep pace with wider societal developments. While the implementation of a new language curriculum was a positive move to realign the curriculum to national aspirations, curriculum change, although desirable, is always complex in its involving a series of obstacles (Bennie \& Newstead, 1999). These include a lack of clarity with respect to the essential expectations and objectives of such change, the boundaries of the content, the methods of teaching, and the assessment criteria. Project work, as an interactive activity, is used in Communicative Language Teaching (CLT) to assist learners to learn communicatively and to build knowledge while they do research. This process of research to which learners are exposed through project work will enhance knowledge-building in that learners will improve on their old knowledge and create new knowledge. For project work in CLT, learners may be asked, for example, to read true-life texts, make notes, or record information in a descriptive way (Miller \& Krajcik, 2019). Knowledge-building can be achieved only if teachers assist learners to do so through facilitation and guidance in project work (UNESCO, 2019).

Knowledge-building in the teaching of English as a second language can be achieved through 
the use of CLT by allowing learners to be interactive. It also gives them the opportunity to put into practice their communication skills and thus create meaningful interaction (Toro et al., 2019). The efforts to implement such new curriculum change, however, are fraught with problems and its implementers are experiencing difficulties using CLT to implement it smoothly (Ngwenya, 2020). In order for teachers to enhance knowledge-building in the new secondary school English Language curriculum, they need to be prepared to use CLT effectively. We sought to explore the level of such preparedness of secondary school teachers to enhance knowledge-building through the use of CLT in implementing the new English Language curriculum in Sri Lankan public schools.

According to the new curriculum, teachers are expected to enhance knowledgebuilding through the use of the CLT approach to produce learners who can create knowledge that will change their behaviour and help them influence their surroundings. Learners are expected to be critical thinkers and problem solvers. The use of the CLT approach may assist learners to build knowledge that will, in turn, assist them to fit into the socio-economic environment when they leave school (Dharmawardene et al, 2021). Bennie and Newstead (1999) carried out a study of obstacles to implementing a new curriculum in mathematics. Some of their findings were that teachers lacked adequate knowledge and that learners did not have the preknowledge that could serve as a foundation for the new curriculum. A study by Mandukwini (2016) on challenges surrounding curriculum implementation in high schools in Mount Fletcher District, Eastern Cape, South Africa, found that there was a lack of resources and that teachers had heavy workloads. Although some of the challenges found in other studies may be similar to those found in Sri Lank, in this research we address a particular issue with regard to the knowledge gap. It would seem that limited research in the Sri Lankan secondary school context has investigated the teachers' preparedness to enhance knowledge-building in the new curriculum at secondary school level through the CLT approach. It is against the above background that we undertook our study.

The following research question guided it.

What is the level of preparedness of secondary school teachers in Sri Lank to enhance knowledge-building through the CLT approach in relation to the new curriculum? 


\section{Literature review}

According to Ma et al., (2019), knowledge-building is viewed as giving learners collective responsibility for improving ideas they care about. Scardamalia and Bereiter (2006) have described knowledge-building as an attempt to modify education in an important way so that it becomes an intelligible effort to induct students into a knowledge producing culture. We define knowledge-building in terms of learners working collaboratively to produce and improve knowledge and ideas. In language teaching, one of the best ways of enhancing knowledge-building is the CLT approach that is defined as a method of teaching using communication for learners to express their ideas, feelings, and thoughts (Toro et al., 2019).

Richards (2006, p. 2) defined CLT as an approach to foreign or second language teaching that

emphasizes that "the goal of language learning is communicative competence." Littlewood (1981, p. 1) elucidated that "one of the most characteristic features of communicative language teaching is that it pays systematic attention to functional as well as structural aspects of language, combining these into a more fully communicative view." Moss and Ross-Feldman (2003) stated that CLT is any activity given to the learners that involves using communication to speak to and listen to their peers. We conclude that CLT is an approach that uses communication for learners to develop and create knowledge and to express ideas about specific topics under discussion. Given this definition of CLT it is imperative that teachers enhance knowledge-building by using activities that are interactive. Celce-Murcia (1991) and Littlewood (1981) suggested that activities include role play, group discussions, watching videos or films, answering guided questions, debates, jigsaw activities, and question and answer sessions in teaching. These activities help learners to build knowledge through interaction with others. The CLT approach is recommended in the new Sri Lankan curriculum and resonates well with knowledge-building since it can be used by teachers to assist learners in creating new knowledge through interaction. First, the use of CLT in the new curriculum helps both teachers and learners to achieve knowledge-building through teacher-to-learner and learner-to-learner interaction (Maarof, 2018). Second, CLT assists in knowledge-building because learners are responsible for their own learning as they produce their own knowledge and ideas, while teachers act only as facilitators. Learning English as a second language will 
occur as a result of learners' interaction in creative knowledge work (Ma et al., 2019). Teaching and learning methods such as doing field work, demonstrations, simulations, and role play along with engaging in group work, projects, drama, debates, and research should therefore be used for knowledge-building in English second language classes (Maarof, 2018). It will be difficult for learners not to learn if they participate in authentic knowledge creation. We, therefore, sought to explore the preparedness of secondary school teachers to enhance knowledge-building through the implementation of the CLT approach in the new English Language curriculum.

Socio-cultural Theory (SCT) (Vygotsky, 1978) and Experiential Learning Theory (ELT) (Kolb, 1984) were adopted in this study because both reverberate well with knowledge-building and CLT through the aspects of interaction, scaffolding, and collaborative learning in the creation of new knowledge. The core concepts of the two theories maintain that learners' critical thinking levels originate from the collaborative learning or interaction they have with their peers before they transfer to an individual's thinking level (Wertsch, 2008; Xiangui, 2005). These theories share the view that interaction is one of the key elements that help learners to construct new ideas and knowledge. This is supported by Brown and Gaskins (2014), and Luna Scott (2015) who claimed that new knowledge may be constructed when learners socialize with their peers. This implies that for teachers to help learners in knowledge-building, participatory activities, talk, and collaborative work should be used in English lessons (Cross, 2010; Vygotsky, 1978). This may be done if the teacher uses the recommended CLT activities that help learners to work together and build knowledge.

The principles of SCT and ELT are based on learners being given challenging activities to facilitate learning. Learners should work cooperatively on given activities that expose them to new information, and that assist them to contribute to, adopt, and circulate the new knowledge to their peers (Knutson, 2003). Both SCT and the ELT activities given to learners should form part of the learners' experiences, thus building knowledge. The two theories can illuminate how the learner and the teacher build new knowledge through interaction, a tenet of CLT (Kolb, 1984; Vygotsky, 1978). The core aspects of these two theories guided us in analyzing the data. 


\section{Methodology}

The study was qualitative in nature. Gay et al., (2011, p. 7) have stated that "qualitative research is the collection, analysis and interpretation of comprehensive narrative (i.e., nonnumerical) data to gain insights into particular phenomenon of interest." Therefore, the qualitative research we undertook sought to probe deeply into the research setting to obtain an in-depth understanding of the preparedness of the secondary school teachers to implement the new curriculum using CLT in knowledgebuilding. Data was collected and triangulated through non-participatory observations and semi-structured interviews with teachers. We conducted the interviews and nonparticipant observations to obtain information about the teachers' preparedness to implement the new curriculum using the CLT approach. During observations we acted as outsiders and made sure that we did not interfere during the lessons. We brought into the classroom the observation checklist that guided us in recording information on the preparedness of teachers in knowledge-building using CLT. Nonparticipant observation was the main data collection instrument while we used interviews to crosscheck if teachers were adequately prepared and were implementing the new curriculum to assist learners in knowledge-building.

We were concerned to collect rich data so that we could use it inductively to develop insights and generalizations from it. In this way teachers' preparedness was brought out clearly. Both data sets helped us to understand the extent of the teachers' preparedness to implement the new

curriculum using the recommended CLT approach. Five participants were purposively selected. The criteria used were that they had to be holders of a Postgraduate Diploma in Education and had to have been teaching prior to the introduction of the new curriculum. The sample was comprised of five teachers from five secondary schools in Colombo district in Sri Lanka.

\section{Findings}

Through the interviews held with the teachers and the observations we made, the level of the teachers' preparedness to implement CLT to build new knowledge emerged. The main findings of this study show that the teachers' preparedness to enhance knowledge-building through the implementation of CLT in the new curriculum was affected by a lack of resources and teaching materials, poor planning, overly large groups, insufficient time, and the high demands of the new English 
curriculum. Through the observations we established how teachers' enhanced knowledge-building in learners through the use of CLT in their classrooms, while the interviews cross checked their understanding of how they should enhance knowledge given the expectations of the new curriculum.

The main obstacle to enhancing knowledge through the use of CLT for knowledgebuilding was the shortage of textbooks and teaching aids. All the participants felt that the new curriculum was less planned. Communicative language teaching had always been recommended but because of the lack of resources, it was not implemented appropriately.

From the findings it is clear that the participants agreed that the new curriculum could have brought changes to the activities and methods used. However, teachers still do not have the resources and, as a result, it is difficult for them to teach learners using interactive activities like group work, role play, and discussions. While they agreed that communicative language teaching activities can assist learners to build and create new knowledge, they attributed the poor implementation of CLT to a lack of resources. This finding confirm those of Richards and Rodgers (2014) who noted that it is difficult to build knowledge through CLT when there is a dearth of resources. Teachers indicated that it was now expensive to buy papers and permanent markers to make simple learning aids like work cards that could assist learners to interact effectively and build new knowledge. These finding agree with those of Esau and Mpofu (2017) who claimed that curriculum implementation could not be done successfully if adequate resources for implementation were not in place.

During the interviews, the participants indicated that too little time was allocated to teach English Language. They said that double periods were required to teach the subject meaningfully and interactively since it was impossible for learners to build new knowledge within the short periods provided for in the timetable.

One participant explained that the new curriculum did not change the time allocation of subjects, but it added more content. The findings reveal that the time factor has affected the teacher's preparedness to enhance knowledge-building through CLT. All the participants agreed that the CLT approach worked well and assisted in knowledge-building. They highlighted that perhaps they could have been in a position to use it if they were not required to meet the demands of the Ministry of Education. The teachers are under pressure to cover the syllabus, but the limited time allocated 
for the teaching of English Language compromises the quality of education since the time for learners to build knowledge is limited. This finding is similar to Chang's (2011) who found that CLT activities are time consuming, and that it takes time for teachers to explain how to do given tasks. It would appear that the time factor has adversely affected knowledge-building through the use of CLT in curriculum implementation in Harare Metropolitan secondary schools. Difficulties with implementing group work as a recommended teaching method

The new curriculum recommends the use of the CLT approach in the teaching of English Language to enhance knowledge-building. However, the findings in this study show that teachers used mainly group work as the preferred activity because they found it easier to manage. We observed that the teachers divided the learners into large groups of eight to ten, which did not positively impact individual performances in knowledge-building. We found that the groups were too large for communicative learning to take place. As a result, some learners did not participate but played around while one or two members in the group did the work. We also presumed that the teachers had challenges in organizing and monitoring all the learners in a large group during the learning process. These findings agree with those of Burke (2011) and Chang (2011) who found that large groups were ineffective in relation to interaction since learners' chances of participation were reduced, thus suppressing knowledge building. Participants agreed that the interactive activities recommended in the new curriculum were not easy to use because all learners in the large groups were not able to participate. This is in line with Coskun's (2011) finding that teachers did not have the relevant skills to apply and use CLT interactive activities to enhance knowledge for large groups.

All examined lessons revealed that learners are restricted to answering questions and receiving commands from the teacher and this does not support the principle of CLT and knowledge-building during which process learners are required to create knowledge and negotiate meaning. Learners were not given opportunities to engage in prolonged interactions with the teacher and they were given even fewer opportunities to interact among themselves. Teachers asked simple questions which allowed learners to give factual answers.

Once the teachers found that learners knew the answers they were satisfied and did not require any additional information from them. This kind of teaching did not 
enable learners to interact effectively nor to develop the desired language skills. AlZahrani and Al-Bargi (2017) proposed that teachers should engage their learners by asking the kinds of questions that enable them to interact and build knowledge; this was not the case in the classes we observed. We could see that the participants employed more traditional methods of teaching and it appeared as though they were not conversant with the CLT approach.

During the class observations we noticed that teachers used a lot of drilling or rote learning, but this is not recommended in the new curriculum as a way of building knowledge. Learners were asked to repeat through speaking together in order to memorise what they were being taught. Once a learner gave the correct answer, the entire class repeated it. Participants conceded to the use of repetition as a way of assisting learners to grasp what they were being taught. They believed that repetition assisted learners to commit this to memory for examination purposes. Rote learning, repetition, and memorizing stands in stark contrast to knowledge-building that is based on learners constructing their own knowledge through interaction (Mertens, 2014; Thomas, 2017).

The findings of this study show that teachers did not have the capacity in terms of knowledge and skills to use CLT to enhance knowledge-building and were therefore ill prepared to do so. Prior to the introduction of the new curriculum teachers needed to attend empowering workshops and staff development courses. These would have capacitated them with knowledge and skills in relation to using CLT in implementing the new curriculum. Quyen and Khairani (2017) were of the opinion that teacher knowledge is the biggest factor in the implementation of any new curriculum.

A lack of sufficient knowledge was evident during our observations. Participants still used teacher-centered methods, which did not result in knowledge-building in all the classes we observed. They were not trained in the use of computers for teaching their learners. Participants were more concerned with giving learners information to prepare them for the examinations, and there was no evidence in the learners of any knowledge-building taking place nor was the creation of new knowledge by the learners evident. We concluded that the participants did not use the CLT approach because of the lack of staff development. This meant, of course, that the teachers were ill prepared for the implementation of the new curriculum with its persistence on knowledge-building. Similarly, Schwartz (2006) found that curriculum planners did 
indeed put in place good educational plans, but these were blocked because curriculum users and teachers were not adequately prepared to implement the innovations.

\section{Discussion}

The findings from this study suggest that the teachers were ill prepared to enhance knowledge-building through the implementation of CLT in the new curriculum because of the lack of resources, poor planning, time constraints, their insistence on teacher-centered learning, the lack of the skills to implement group work, and generalized incapacity along with not having been consulted on the development of the new curriculum. As Alsubaie (2016) has reminded us, teachers are important to the planning of any new curriculum because of the knowledge, skills, and capabilities they have. In addition, teachers know what is needed and what works for the curriculum to be successful. In this study teachers believed that since they were the implementers of the curriculum, they could have assisted the Ministry in coming up with realistic time allocation, expectations, objectives, and suitable teaching methods to be included in the curriculum. This would have contributed to the teachers owning and working towards fulfilling the set goals of the new curriculum. The teachers did not approve of the Ministry preparing the curriculum and imposing it on them.

Teachers acknowledged that they were not familiar with the procedures of the new curriculum. For example, they indicated that they were expected to use computers in teaching the curriculum and that they were not familiar with the technology. The teachers also lamented the unavailability of textbooks essential to implementing the new curriculum. They highlighted that their schools could not afford to buy the textbooks and that, in some cases, five classes shared one book. Teachers agreed that they were not well prepared to present the new curriculum. The workshops they attended in preparation to teach the new curriculum effectively were not sufficient. They felt that the workshops were simply a way of conveying

the Ministry's expectations to them.

While the teachers lamented the challenges regarding the implementation of CLT in the new curriculum, they appreciated the inclusion of research as a new area of learning. They applauded the Ministry for including this component because it could help learners to build knowledge. Despite the curriculum changes the findings corroborate those of other studies of this nature. Despite the efforts made by teachers 
to be involved in curriculum planning, nothing has changed, and this means that in spite of this new curriculum, teachers are still not enhancing

knowledge through the use of CLT. However, what is novel in this study, is the cry for deeper engagement and involvement of teachers in curriculum planning.

\section{Conclusion and Recommendations}

In light of the findings and the discussion above, and in an attempt to address a shortage in knowledge enhancement, curriculum planners should seriously consider teacher involvement in the review of the curriculum in 2023. Reconsidering teacher involvement will contribute to teachers taking ownership of a new curriculum and working towards achieving its goals. It will also help the Ministry to achieve its goal of knowledge-building in learners, which form the basis for the change in the Sri Lankan curriculum. Furthermore, MoPSE needs to plan carefully so as to provide the necessary resources prior to implementing a new curriculum. Teachers should be trained and enabled to acquire the necessary skills for the implementation of knowledge-building in accordance with the demands of the new curriculum.

\section{References}

[1] Ahmadi, A. A., \& Lukman, A. A. (2015). Issues and prospects of effective implementation of New Secondary School Curriculum in Nigeria. Journal of Education and Practice, 6(34), 29-39.

[2] Alsubaie, M. A. (2016). Curriculum development: Teacher involvement in curriculum development. Journal of Education and Practice, 7(9), 106107.

[3] Al-Zahrani, M. Y., \& Al-Bargi, A. (2017). The impact of teacher questioning on creating interaction in EFL: A discourse analysis. English Language Teaching, 10(6), 135- 150.

[4] Bennie, K., \& Newstead, K. (1999). Obstacles to implementing a new curriculum. In Proceedings of the national subject didactics symposium (pp. 150-157). University of Stellenbosch.

[5] Bereiter, C., \& Scardamalia, M. (2014). Knowledge building and knowledge creation: One concept, two hills to climb. In S. C. Tan, H. J. So \& J. Yeo (Eds.), Knowledge creation in education (pp. 35-52). Springer.

[6] Brown, P., \& Gaskins, S. (2014). Language acquisition and language socialization. In N. J. Enfield, P. Kockelman \& J. Sidnell (Eds.), Cambridge handbook of linguistic anthropology (pp.187-226). Cambridge University Press.

[7] Burke, A. (2011). Group work: How to use groups effectively. Journal of Effective Teaching, 11(2), 87-95. 
[8] Celce-Murcia, M. (1991). Grammar pedagogy in second and foreign language teaching. TESOL Quarterly, 25(3), 459-480.

[9] Chang, M. (2011). EFL teachers' attitudes toward communicative language teaching in Taiwanese college. Asian EFL Journal, 53(1), 17-34.

[10] Coskun, A. (2011). Future English teachers' attitudes towards EIL pronunciation. Online Submission. Journal of English as an International Language, 6(2), 46-68.

[11] Cross, R. (2010). Language teaching as socio-cultural activity: Rethinking language teacher practice. The Modern Language Journal, 94(3), 434-452.

[12] Denzin, N. K., \& Lincoln, Y. S. (2005). Introduction: The discipline and practice of qualitative research. In N. K. Denzin \& Y. S. Lincoln (Eds.), The Sage handbook of qualitative research (pp.1-32). SAGE.

[13] Dharmawardene, R.P. and Wijewardene, L. (2021) Effectiveness of Teaching in Blended Mode: A Case Study from Sri Lankan University System. Open Access Library Journal, 8, 1-14. doi: 10.4236/oalib.1107883

[14] Esau, H., \& Mpofu, J. (2017). The preparedness of secondary schools to implement the grade 3 new curriculum in Sri Lank: Case study of Bulawayo metropolitan secondary schools. European Journal of Social Sciences Studies, 2(4), 104-116.

[15] Gay, L. R., Mills, G. E., \& Airasian, P. W. (2011). Educational research: Competencies for analysis and applications (10th ed.). Pearson Educational International.

[16] Canagarajah, S. (2011). Code meshing in academic writing: Identifying teachable strategies of translanguaging. The Modern Language Journal, 95(3), 401-417.

[17] Kaiser, K. (2009). Protecting respondent confidentiality in qualitative research. Qualitative Health Research, 19(11), 1632-1641.

[18] Kalas, I., Bannayan, H. E., Conery, L., Laval, E., Laurillard, D., Lim, C. P., Musgrave, S., Semenov, A. \& Turcsányi-Szabó, M. Á. R. T. A. (2012). ICT in secondary education: Analytical survey volume 1: Exploring the origins, settings and initiatives. UNESCO Institute for Information Technologies in Education.

[19] Knutson, S. (2003). Experiential learning in second-language classrooms. Tesl Canada Journaurevue Tesl Du Canada, 20(2), 52-64.

[20] Kolb, D. A. (1984). Experiential learning: Experience as the source of learning and development. Prentice Hall.

[21] Littlewood, W. T. (1981). Communicative language teaching: An introduction. Cambridge University Press.

[22] Luna Scott, C. (2015). The futures of learning 3: What kind of pedagogies for the $21^{\text {st }}$ century? UNESCO education research and foresight.

[23] Ma, L., Resendes, M., Scardamalia, M., \& Dobbie, K. (2019). The knowledge building network pilot project: An exploration of emergent designs to enhance collective teacher efficacy. In K. 
[24] Lund, G. P. Niccolai, E. Lavoué, C. Hmelo-Silver, G. Gweon \& M. Baker (Eds.), A wide lens: Combining embodied, enactive, extended, and embedded learning in collaborative settings, 13th international conference on computer supported collaborative learning (CSCL) 2019, (1), 81-87. International Society of the Learning Sciences.

[25] Maarof, N. (2018). The effect of role-play and simulation approach on enhancing ESL oral communication skills. International Journal of Research in English Education, 3(3), 63-71.

[26] Mandukwini, N. (2016). Challenges towards curriculum implementation in high schools in Mount Fletcher district, Eastern Cape (Unpublished doctoral dissertation). University of South Africa.

[27] Maree, K. (2007). First steps in research. Van Schaik.

[28] Mashele, S. F. (2018). The impact of curriculum change on the working lives of rural teachers (Unpublished doctoral dissertation). University of Pretoria.

[29] Mertens, D. M. (2014). Research and evaluation in education and psychology: Integrating diversity with quantitative, qualitative, and mixed methods. SAGE.

[30] Miller, E. C., \& Krajcik, J. S. (2019). Promoting deep learning through project-based learning: A design problem. Disciplinary and Interdisciplinary Science Education Research, 1(1), 1-10.

[31] Moss, D., \& Ross-Feldman, L. (2003) Second language acquisition in adults: From research to practice. http://. cal.org/caela/esl resources/digests/SLA.html

[32] Mugadzaweta, J. (2017). Teachers' shortage dents curriculum implementation. The Herald, February 15.

https://www.herald.co.zw/teachers-shortage-dentscurriculumimplementation/

[33] Ngwenya, V. C. (2020). Curriculum implementation challenges encountered by secondary school teachers in Bulawayo Metropolitan Province, Sri Lank. Africa Education Review, 17(2), 158-176.

[34] Nkala, S. (2017). Dadaya case against Dokora stalls. Newsday, January 9. https://www.newsday.co.zw/2017/02/dadaya-case-dokora-stalls/

[35] Nziramasanga, C. T. (1999). Report of the presidential commission of inquiry into education and training. Sri Lank Government.

[36] Quyen, N. T. D., \& Khairani, A. Z. (2017). Reviewing the challenges of implementing formative assessment in Asia: The need for a professional development program. Journal of Social Science Studies, 4(1), 160-177.

[37] Rahman, M. M., Pandian, A., \& Kaur, M. (2018). Factors affecting teachers' implementation of communicative language teaching curriculum in secondary schools in Bangladesh. The Qualitative Report, 23(5), 11041126. 
[38] Richards, J. C. (2006). Communicative language teaching today. Cambridge University Press.

[39] Richards, J. C., \& Rodgers, T. S. (2014). Approaches and methods in language teaching. Cambridge University Press.

[40] Scardamalia, M., \& Bereiter, C. (2006). Knowledge building: Theory, pedagogy, and technology. In R. K. Sawyer (Ed.), The Cambridge handbook of the learning sciences (pp.97-118). Cambridge University Press.

[41] Schwartz, M. (2006). For whom do we write the curriculum? Journal of Curriculum Studies, 38(4), 449-457.

https://doi.org/10.1080/00220270500296606 Toro, V., Camacho Minuche, G., Pinza-Tapia, E., \& Paredes, F. (2019). The use of the communicative language teaching approach to improve students' oral skills. English Language Teaching, 12(1), 110-118.

[42] Thomas, G. (2017). How to do your research project: A guide for students. SAGE.

[43] UNESCO. (2005). United Nations decade of education for sustainable development (2005- 2014). UNESCO International Implementation Scheme.

[44] Vygotsky, L. (1978). Mind in society. MIT Press.

[45] Walsh, T. (2016). 100 years of secondary curriculum development and implementation in Ireland: A tale of a swinging pendulum. Irish Educational Studies, 35(1), 1-16.

[46] Wertsch, J. V. (2008). The narrative organization of collective memory. Ethos, 36(1), 120- 135.

[47] Xiangui, Z. (2005). Learning theories and second language learning. CELEA Journal, 28(5), 120-127.

[48] Zhuwau, C., \& Shumba, M., (2018). Factors limiting smooth implementation of new curriculum in rural secondary schools of Sri Lank: Case study of Nyanga north area, Sri Lank. The International Journal of Humanities \& Social Studies, 6(11), 198- 207. 